3. Dilawari JB, Chawla YK. Pseudosclerosing cholangitis in extrahepatic portal venous obstruction. Gut 1992;33:272-6.

4. Chandra R, Kapoor D, Tharakan A, Chaudhary A, Sarin SK. Portal biliopathy. J Gastroenterol Hepatol 2001;16: 1086-92.
5. Khuroo MS, Yatoo GN, Zargar SA, et al. Biliary abnormalities associated with extrahepatic portal venous obstruction. Hepatology 1993;17:807-13.

6. Vibert E, Azoulay D, Aloia T, et al. Therapeutic strategies in symptomatic portal biliopathy. Ann Surg 2007;246:97-104.

\title{
IMAGE
}

\section{Pedunculated extra hepatic biliary cystadenoma mimicking as a stone}

An eighteen year old female presented with right upper quadrant pain and jaundice of six months duration. Physical examination revealed icterus and hepatomegaly. Bilirubin and alkaline phosphatase were elevated suggesting cholestasis. Ultrasound abdomen showed multiple gall stones with dilated intra-hepatic biliary radicals (IHBR) due to a mixed echogenic lesion in the common hepatic duct (CHD) suspicious of stone. Magnetic resonance cholangiopancreatogram showed dilated IHBR and hyper intense lesion within the CHD. With a provisional diagnosis of CHD stone, ERCP was done with therapeutic intention which revealed a well defined filling defect in the CHD suggestive of a calculus (Fig. 1). Attempts to remove the stone failed and she was taken up for open cholecystectomy and bile duct exploration. At surgery CHD was filled with a solid soft tissue lesion. Choledochotomy was done and a $5 \mathrm{~cm}$ oblong soft tissue lesion popped out of the choledochotomy wound. It was attached to the anterior wall of the CHD by a narrow base. The lesion was completely removed and a completion choledochoscopy was

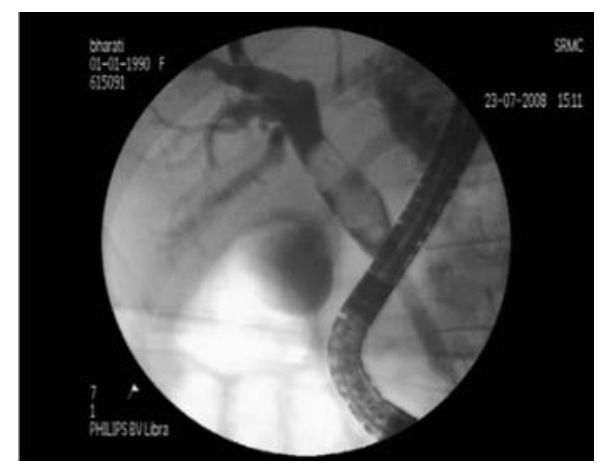

Fig. 1 ERCP- an oblong filling defect in the common hepatic duct resembling a stone done to confirm the clearance. Pathologist reported it as a mucinous cystadenoma

Cystadenomas of the biliary tract are rare entities that have predilection to affect middle age females. ${ }^{1,2}$ Hepatobiliary cystadenoma could be mistaken for hydatid cyst or choledochal cyst or simple liver cyst. Multiseptated cystic appearance is the classical radiological appearance of hepatobiliary cystadenoma. ${ }^{3}$ The case presented here is interesting as it was misdiagnosed as a stone. Misinterpretation of the lesion as a stone was due to the well encapsulated and pedunculated nature of the lesion that occupied the common hepatic duct with extension into the left ductal system. Pedunculated biliary cystadenoma has not been reported in the literature.

S. Sankar ${ }^{1}(\bowtie) \cdot$ M. Subramanian ${ }^{1} \cdot$ Leena Dennis Joseph $^{2} \cdot$ S. Rajinikanth ${ }^{3} \cdot$ Venu Nandigam ${ }^{1}$ ${ }^{1}$ Department of Surgical Gastroenterology,

${ }^{2}$ Department of Pathology,

${ }^{3}$ Department of Medical Gastroenterology, Sri Ramachandra Medical College \& Research Institute, Chennai, India S. Sankar $(\square)$
drsshankar@gmail.com

\section{References}

1. Ishak KG, Willis GW, Cummins SD, Bullock AA. Biliary cystadenoma and cystadenocarcinoma: report of 14 cases and review of the literature. Cancer 1977;38:322-38.

2. Davies W, Chow M, Nagorney D. Extra hepatic biliary cystadenomas and cystadenocarcinoma. Report of seven cases and review of the literature. Ann Surg 1995;222:619-25.

3. Korobkin M, Stephens DH, Lee JK, et al. Biliary cystadenoma and cystadenocarcinoma: CT and sonographic findings. AJR Am J Roentgenol 1989;153:507-11. 